\title{
Sweet new route to acrylonitrile
}

The nitrilation
reaction
produces
acrylonitrile
in high yield
using a cheap
catalyst from
a bio-based
renewable
starting
material

Acrylonitrile is an important commodity chemical. It is used as a precursor to polyacrylonitrile, often used for the production of carbon fibres. The high global demand for acrylonitrile - over 6 million tonnes of it were produced last year - is only going to get higher, given increasing interest in using carbon fibres in strong, lightweight products, such as vehicle components.

The Sohio process - which converts propylene from crude oil into acrylonitrile by ammoxidation over a bismuth molybdate-based catalyst - was originally developed in the 1950s. Now, writing in Science, Gregg Beckham and co-workers (who are part of a US Department of Energy-sponsored renewable carbon fiber consortium) describe a process for renewable acrylonitrile production from microbial sugars. "We were keen to develop a new approach that could use renewable feedstocks," explains Beckham. "Besides being relatively low yielding

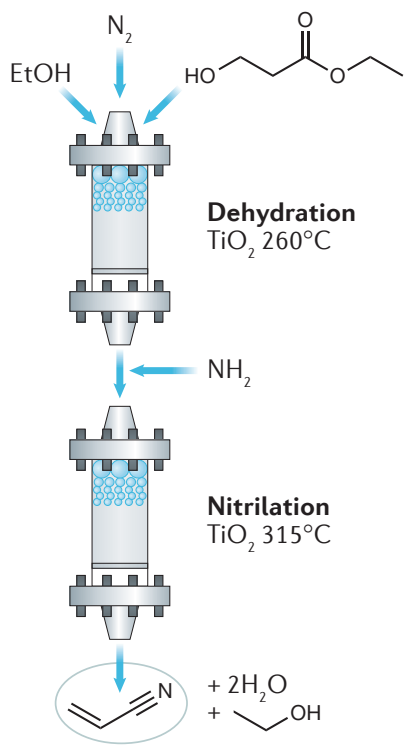

Adapted with permission from Karp, E. M. et al. (2017), AAAS. (for a petrochemical process), the ammoxidation reaction produces hydrogen cyanide as a by-product and is highly exothermic, such that it requires sophisticated process control. We wanted to develop a method that didn't rely on fossil fuels and address these issues."

Previous attempts to use biobased feedstocks have focused on the use of sugars derived from lignocellulosic biomass, but have been relatively low yielding. "We were inspired by earlier, mostly ignored, reports that acids and esters could be converted directly to nitriles over acid catalysts," explains Eric Karp, first author of the study, "this hadn't been applied to the synthesis of acrylonitrile, but we knew we could get 3-hydroxypropionic acid (3-HP) from microbial cultivation and knew that it could be dehydrated easily."

In industrial processes, esters are preferred to carboxylic acids as they are less corrosive and more volatile. Heating ethyl 3-hydroxypropionate with ammonia over a titania catalyst eventually gives acrylonitrile. Ethyl acrylate is the main product below $230^{\circ} \mathrm{C}$, while acrylonitrile can be favoured by raising the temperature to $320^{\circ} \mathrm{C}$. It is proposed that ethyl 3-HP is dehydrated first to ethyl acrylate, followed by aminolysis to produce acrylamide and then a further dehydration affords acrylonitrile. "The nitrilation reaction produces acrylonitrile in high yield using a cheap catalyst from a bio-based renewable starting material," says Karp. "The process is endothermic, with only water and ethanol as by-products." The nitrilation reaction thus converts the inherently oxygenated biomass feedstock whereas ammoxidation requires a hydrocarbon substrate.

Beckham and co-workers go on to propose a potential industrial-scale process with some modifications to their initial benchtop method. 3-HP would be extracted from a microbial cultivation broth using ethanol. A reactive distillation affords ethyl acrylate directly, is fed into the next step to produce acrylonitrile. In addition, the aminolysis reaction can be performed using pure ammonia rather than ammonia diluted with nitrogen. It is predicted that a scaled process would produce acrylonitrile at a price similar to that which we pay today, but with less price variation and lower greenhouse gas emissions because the technology is independent of fossil fuels.

The next step is to scale up the process and use the acrylonitrile in the production of polyacrylonitrile and, ultimately, carbon fibre. "We need to compare the performance of bio-based carbon fibre with that of petroleum-based carbon fibre," explains Beckham. "We need to know whether and how impurities from biomass affect the properties of the carbon fibre compared to the industry standard." Beckham and co-workers are also keen to investigate the production of acrylonitrile from lactic acid. The dehydration step is expected to be much more difficult than for 3-HP, but it is easier to obtain. "Lactic acid is already used in the production of biodegradable polylactic acid ," he says. "Humanity has been making lactic acid for as long as we've been making ethanol to drink, so we're working on another new route to acrylonitrile again inspired by some decades-old work."

Stephen G. Davey

ORIGINAL ARTICLE Karp, E. M. et al. Renewable acrylonitrile production. Science 358, 1307-1310 (2017)

FURTHER READING Spevacek, J. A change is gonna come. Nat. Rev. Chem. 1, 0008 (2017) 